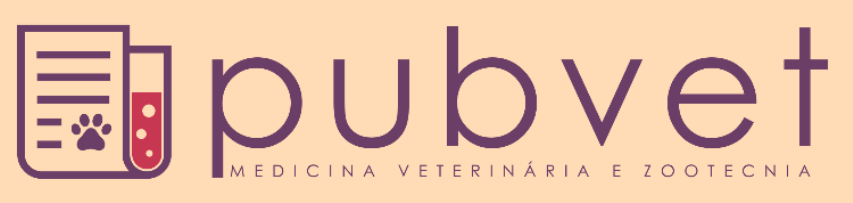

https://doi.org/10.31533/pubvet.v13n3a275.1-7

\title{
Influência do processo de classificação dos ovos sobre índices de produtividade de um incubatório industrial
}

\author{
Matheus Henrique Galdino Carvalho ${ }^{1}$, Igor Leonardo Vespucci ${ }^{2 *}{ }^{\circ}$, Milanna Paula Cabral \\ Nunes $^{3}$, Deyner Damas Aguiar Silva ${ }^{\circ}$
}

${ }^{1}$ Engenheiro Agrônomo, Faculdade Montes Belos, São Luis de Montes Belos/GO - Brasil.

${ }^{2}$ Doutorando, Departamento de pós-graduação em Agronegócio, Universidade Federal de Goiás - Goiânia/GO - Brasil.

${ }^{2}$ Mestranda, Departamento de pós-graduação em Engenharia Agrícola, Universidade Estadual de Goiás - Anápolis/GO - Brasil.

${ }^{3}$ Doutorando, Departamento de Ciências Agrárias, Instituto Federal Goiano - IF Goiano - Rio Verde/GO - Brasil.

*Autor para correspondencia, E-mail: igorvespucci@agronomo.eng.br.

Resumo. O presente trabalho tem por objetivo avaliar a viabilidade do processo de repasse ou não dos ovos na granja sobre os efeitos na incubação artificial. Para avaliar essa prática, foram estudados os índices de produtividade de 3.072 ovos, divididos em duas categorias: ovos classificados e não classificados. Determinaram-se índices de fertilidade, eclodibilidade, mortalidade embrionária e contaminação. Os índices de eclodibilidade e fertilidade em relação ao número total de ovos sofreu influência em relação ao processo de classificação $(\mathrm{P}<0,05)$. Houve diferença estatística significativa do tipo de processo para a mortalidade embrionária conforme a fase de incubação. A mortalidade embrionária foi menor para os ovos que sofreram o processo de classificação. Não houve diferença estatística significativa para o índice de contaminação. Os resultados sugerem que os ovos que passam por processo de classificação apresentam melhores índices de eclodibilidade e mortalidade embrionária.

Palavra-chave: incubação, manejo, matrizes

\section{Influence of the egg classification process on productivity indexes of an industrial hatchery}

\begin{abstract}
The present work has the objective of evaluating the viability of the process of transfer or not of the eggs in the farm on the effects in the artificial incubation. To evaluate this practice, the productivity indexes of 3,072 eggs were studied, divided into two categories: classified and unclassified eggs. Fertility, hatchability, embryonic mortality and contamination rates were determined. The hatchability and fertility indexes in relation to the total number of eggs were influenced in relation to the classification process $(p<0.05)$. There was a significant statistical difference in the type of process for the embryonic mortality according to the incubation phase. Embryo mortality was lower for the eggs that underwent the classification process. There was no significant statistical difference for the contamination index. The results suggest that eggs that go through the classification process have better hatchability and embryonic mortality rates.
\end{abstract}

Keywords: incubation, management, breeding broilers 


\title{
Influencia del proceso de clasificación de los huevos sobre los índices de productividad de una incubadora industrial
}

\begin{abstract}
Resumen. El presente trabajo tiene por objetivo evaluar la viabilidad del proceso de repaso o no de los huevos en la granja sobre los efectos en la incubación artificial. Para evaluar esta práctica, se estudiaron los índices de productividad de 3.072 huevos, divididos en dos categorías: huevos clasificados y no clasificados. Se determinaron índices de fertilidad, eclosión, mortalidad embrionaria y contaminación. Los índices de eclosión y fertilidad en relación con el número total de huevos tuvieron influencia en el proceso de clasificación $(p<0,05)$. Se observó una diferencia estadística significativa del tipo de proceso para la mortalidad embrionaria según la fase de incubación. La mortalidad embrionaria fue menor para los huevos que sufrieron el proceso de clasificación. No hubo diferencia estadística significativa para el índice de contaminación. Los resultados sugieren que los huevos que pasan por el proceso de clasificación presentan mejores índices de eclosión y mortalidad embrionaria.
\end{abstract}

Palabras clave: incubación, manejo, matrices

\section{Introdução}

$\mathrm{O}$ aumento da demanda de produtos de origem avícola e o constante crescimento do mercado, faz com que as empresas do setor aumentem sua produtividade. Para isso, incubam a maioria dos ovos produzidos nas granjas de matrizes, inclusive os ovos com problemas de cascas, trincados, sujos e deformados. Para o bom nascimento de pintinhos o processo inicia-se por manejo adequado na coleta de ovos dentro da granja e seu transporte até o incubatório, além do processo de classificação dos ovos, no qual consiste em selecionar ovos considerados como incubáveis (Santos et al., 2007).

Normalmente ovos com pouca chance de eclosão e que impliquem em pintinhos de baixa qualidade são descartados. Os ovos de boa qualidade devem ser provenientes de aves saudáveis, livre de microrganismos, boa espessura de casca, forma ovoidal, ser em férteis e não apresentar deformidade e trincas (Cobb-Vantres, 2008). Existem algumas características do ovo que podem afetar a obtenção de pintos viáveis. A porosidade e espessura da casca são fatores de grande influência no desenvolvimento embrionário (Narushin \& Romanov, 2002) e que há uma associação entre a qualidade da casca e a incubabilidade. Alguns problemas na qualidade da casca são capazes de determinar perdas significativas para a indústria de produção de ovos (Peebles \& McDaniel, 2013).

A qualidade da casca dos ovos tem sido a principal preocupação para a avicultura de ovos férteis. Estima-se, que 10 a $15 \%$ dos ovos produzidos sejam perdidos por apresentarem má qualidade de casca (Cutts et al., 2007). A presença de casca sólida e com boa qualidade é fundamental para o desenvolvimento adequado do embrião.

Mediante o exposto, deseja-se elucidar quais os tipos de ovos que devem ser descartados antes da incubação. Portanto, o objetivo deste trabalho foi avaliar a viabilidade do processo de repasse ou não dos ovos na granja sobre os efeitos na incubação artificial.

\section{Material e métodos}

O projeto foi desenvolvido no Incubatório comercial situado no município de Paraúna/GO no período de 01 de agosto a 01 de setembro de 2018. Utilizaram-se ovos de matrizes pesadas com 30 semanas de idade pertencentes à linhagem Cobb 500. O delineamento experimental foi inteiramente casualizado com dois tratamentos: (T1) ovos classificados e (T2) não classificados contendo 1.536 ovos cada. Para o T2 não foi submetido ao processo de classificação, que consiste na retirada de ovos que apresentavam trincas, sujeiras de sangue ou fezes, deformidades ou casca fora do padrão. Para os ovos com processo de repasse foi feita a seleção conforme padrão da empresa, sendo retirados os ovos que apresentavam trincas, sujeiras de sangue ou fezes, deformidades ou com casca fora do padrão para posterior incubação.

Na granja ambos os ovos foram colocados na sala de fumigação e desinfetados com paraformaldeído na concentração de $10 \mathrm{~g} / \mathrm{m}^{3}$ e em seguida foram transportados com caminhão apropriado para o 
incubatório. No incubatório os ovos foram armazenados na sala de estoque, onde permaneceram por três dias, em temperatura controlada de 18 a $20{ }^{\circ} \mathrm{C}$ para posterior incubação. Posteriormente encaminhados ao pré-aquecimento por 12 horas antes da incubação em sala específica para finalidade a uma temperatura média de $26^{\circ} \mathrm{C}$. Os ovos de cada tratamento foram dispostos em 16 bandejas com 96 ovos e realizado a ovoscopia em ambiente escuro com a utilização de uma mesa com uma luz de pouca intensidade em que há passagem de um feixe de luz (Figura 1).

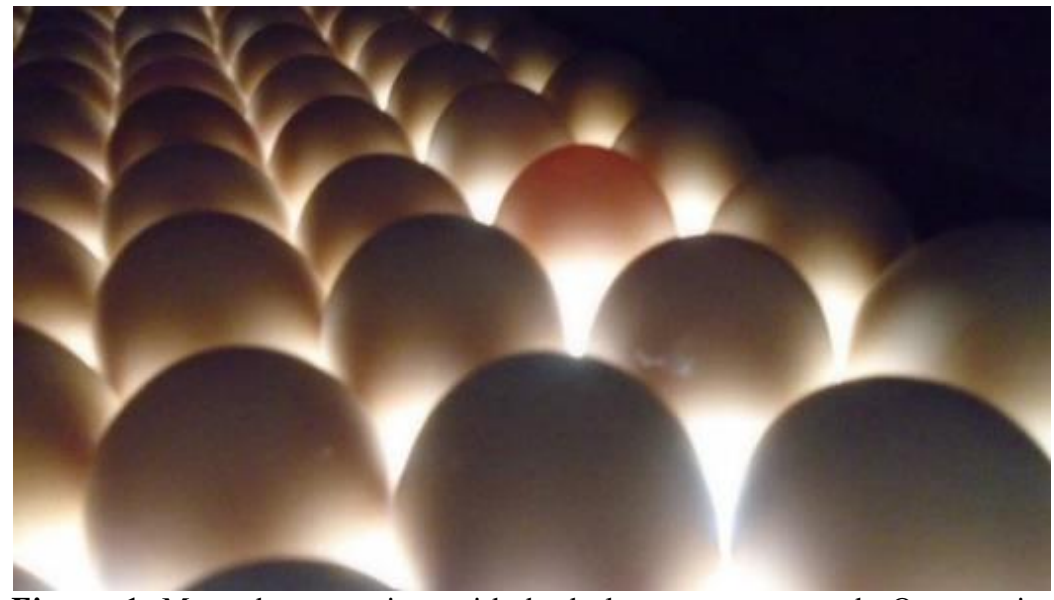

Figura 1. Mesa de pouca intensidade de luz no momento da Ovoscopia.

Após serem identificados de acordo com os tratamentos, os ovos foram pulverizados com amônia quaternária na dosagem de 10 gramas a cada 5 litros de água, sendo em seguida distribuídos dentro da incubadora (modelo CMG 125 HT - CASP), de estágios múltiplos, com capacidade para 124.416 ovos (Figura 2). A incubadora possuía sistema para viragem automática dos ovos a cada hora e painel para controle da temperatura e monitoramento da umidade relativa. Durante a incubação foi usado o esquema de fumigação com paraformoldeído $(200 \mathrm{ml})$ aos 7 e 14 dias. Para a transferência foi aplicado amônia quaternária na dosagem de $1 \mathrm{ml}$ por litro de água.

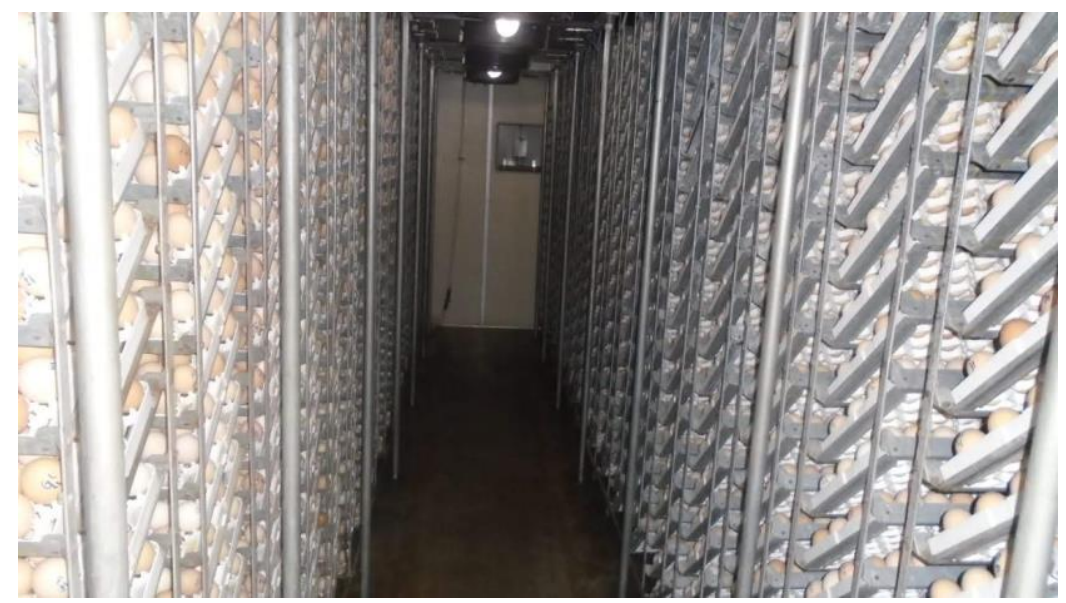

Figura 2. Incubadora de múltiplos estágios.

No $11^{\circ}$ dia de incubação todas as bandejas foram colocadas em um ovoscópio posicionado no corredor da máquina de incubação. Os ovos claros foram retirados e quebrados, sendo identificados os ovos inférteis e aqueles com embriões mortos. Os dados foram registrados para posteriormente serem incluídos na análise final de mortalidade embrionária e fertilidade.

Na transferência para os nascedouros (modelo G 21 HT - CASP), os embriões foram vacinados via ovo contra a doença de Marek e Gumboro (Figura 3). Em seguida, todas as bandejas foram enumeradas e identificadas para correta identificação no nascedouro.

A retirada dos pintos do nascedouro ocorreu com 21 dias (504 horas) de incubação. Após o nascimento foram levados a sala de pintos com temperatura média $27^{\circ} \mathrm{C}$ para a contagem dos nascidos 
e retirada dos ovos não eclodidos. O número de ovos não eclodidos de cada bandeja foi registrado, sendo os mesmos examinados para se determinar o percentual de ovos inférteis, ovos bicados (pintos que não conseguiram eclodir) e a fase em que ocorreu a mortalidade embrionária, incluindo a observação sobre mau-posicionamento e anormalidades morfológicas e conformacionais.

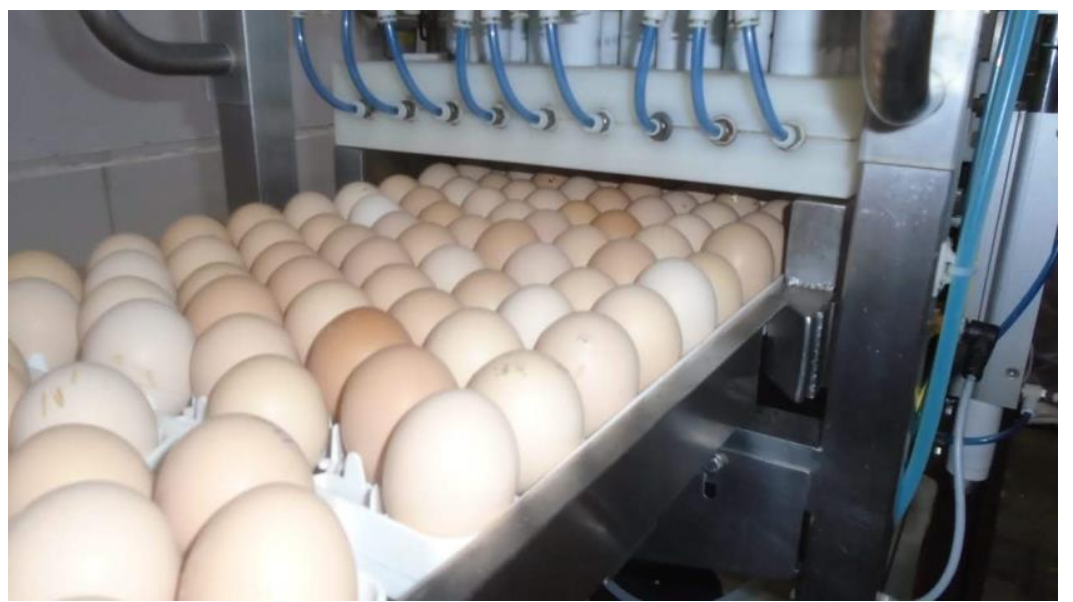

Figura 3. Vacinação via ovo contra as doenças de Marek e Gumboro.

Os ovos inférteis foram identificados no momento da ovoscopia e no embriodiagnóstico ao final do período de incubação. A taxa de eclosão em relação ao número total de ovos férteis, expressa em percentual, foi calculada dividindo-se o número total de pintos nascidos pelo número total de ovos férteis, e multiplicando-se por 100.

A determinação das idades em que ocorreram as mortalidades embrionárias e a identificação dos ovos inférteis foi realizada ao final do período de incubação em todos os ovos não eclodidos de cada repetição dos tratamentos. Estas avaliações foram realiadas de acordo com os critérios utilizados na rotina do incubatório (embriões que morrem entre zero a sete dias, entre oito a 14 dias, entre 15 a 18 e entre 19 a 21 dias de incubação; além de bicados (vivo e morto), contaminados, fungo e desidratado). Após esta análise, os dados de mortalidade inicial e ovos inférteis obtidos aos $11^{\circ}$ dias na ovoscopia foram somados, sendo então calculados o percentual de mortalidade embrionária em relação aos ovos férteis incubados e o percentual de fertilidade em relação ao total de ovos incubados.

Os dados foram submetidos à análise de variância (ANOVA) e as médias comparadas pelo teste T. Para as variáveis não paramétricas foram feitas utilizando o teste Mann Whitney. Foi utilizado o website VassarStats a 5\% de probabilidade.

\section{Resultados e discussão}

Os dados de percentual de eclosão e fertilidade em relação ao número total de ovos incubados encontram-se na Tabela 1. Verifica-se que completado os 21 dias de incubação, a eclodibilidade e fertilidade em relação ao número total de ovos sofreu influência em relação ao processo de classificação $(\mathrm{P}<0,05)$. Observa-se que a eclosão dos ovos com o processo de classificação foi superior aos ovos não classificados em $13 \%$.

Tabela 1. Percentual de eclosão e fertilidade em relação ao número total de ovos incubados segundo os tratamentos

\begin{tabular}{lcc}
\hline & $\%$ eclosão & $\%$ fertilidade \\
\hline Classificados & $90,01 \mathrm{a}$ & $98,32 \mathrm{a}$ \\
Não classificados & $78,25 \mathrm{~b}$ & $95,32 \mathrm{~b}$ \\
\hline Valor $<\mathrm{P}$ & $<0,0001$ & $<0,0001$ \\
\hline
\end{tabular}

Médias seguidas de letra iguais na coluna não diferem pelo teste $\mathrm{T}(\mathrm{P}<0,05)$.

Os ovos sem classificação podem apresentar problemas tais como: qualidade e forma anormal da casca, além de sujidades que causam contaminação. A casca é extremamente importante sobre a 
eclodibilidade, pois afeta o desenvolvimento embrionário. A casca com boa qualidade dificulta a contaminação por patógenos, protege o ovo de choque mecânico, regula a troca de gases entre o interior dos ovos e o ambiente e evita a perda excessiva de água (Carvalho et al., 2007). A forma do ovo também pode influenciar as condições requeridas para uma ótima incubação. Outros autores (Rovaris et al., 2014; Santos et al., 2007) estudando a incubação de ovos com diferentes defeitos (trincados e deformados) obtiveram melhores índices de eclosão em ovos dentro da normalidade, sendo os resultados semelhantes ao encontrado neste trabalho.

O processo de classificação dos ovos está diretamente relacionado à fertilidade dos ovos. Observase que houve diferença entre os ovos classificados e não classificados. Os ovos classificados foram 3\% superior para a fertilidade em relação aos não classificados. Diferentemente de Santos et al. (2007) que não encontraram efeito sobre a fertilidade para ovos considerados fora da normalidade.

$\mathrm{Na}$ Tabela 2 encontram-se os dados referentes à mortalidade embrionária total e separadas por cada fase, sendo de 0 à 7 , de 8 à 14, de 15 à 18 e de 19 à 21 dias de incubação, calculados sobre o número de ovos férteis de acordo com o processo. Houve diferença quanto ao tipo de processo para a mortalidade embrionária conforme a fase de incubação. A mortalidade embrionária foi menor para os ovos que sofreram o processo de classificação. Estes resultados sugerem que ovos que não sofrem processo de repasse e tem problemas como rachaduras e deformidade na casca, aumentam a mortalidade embrionária; concordando com Narahari et al. (2000) que afirmam que danos na casca aumentam a mortalidade embrionária devido à desidratação do embrião provocada por um aumento da perda evaporativa através das lesões da casca.

Tabela 2. Porcentual de mortalidade embrionária total e separados, de zero a sete, de oito a 14, de 15 a 18 dias, de 19 a 21 dias de incubação, calculados sobre o número de ovos férteis de acordo com tipo de processo de classificação

\begin{tabular}{lccccc}
\hline & 0 a 7 dias & 8 a 14 dias & 15 a 18 dias & 19 a 21 dias & Total \\
\hline Classificados & $3,81 \mathrm{a}$ & $0,38 \mathrm{a}$ & $0,50 \mathrm{a}$ & $2,00 \mathrm{a}$ & $6,69 \mathrm{a}$ \\
Não classificados & $6,63 \mathrm{~b}$ & $0,88 \mathrm{a}$ & $1,00 \mathrm{a}$ & $7,00 \mathrm{~b}$ & $16,25 \mathrm{~b}$ \\
\hline$P<$ Value & 0,0026 & 0,0901 & 0,500 & $<0,0001$ & $<0,0001$ \\
\hline
\end{tabular}

Médias seguidas de letras iguais na coluna não diferem pelo teste Mann Whitney $(\mathrm{P}<0,05)$.

$\mathrm{Na}$ fase de zero a sete dias de incubação encontra-se maior mortalidade embrionária para ovos que não sofreram o processo de repasse. Segundo Scarton (2011) nesse período existe alta sensibilidade do embrião, pois ocorre à formação do alantoide, órgão respiratório responsável pela eliminação do dióxido de carbono e pelo aporte de oxigênio ao embrião. Exposição de embriões a concentrações altas de dióxido de carbono pode reduzir, em algumas fases de incubação, a taxa de eclosão (Mauldin, 2001).

Não houve diferença estatística significativa para o processo de repasse no período de 8 à 14 dias, o mesmo relatado por Francisco et al. (2013). De acordo com Pedroso et al. (2006) a mortalidade embrionária entre o oitavo e décimo oitavo dias de incubação pode não estar ligado a idade da matriz e/ou o tempo de incubação de ovos férteis. Portanto, ele cita que a umidade no interior da incubadora, contaminações e nutrição das matrizes pode estar ligado ao processo de mortalidade.

Já para mortalidade tardia de 19 a 21 dias de incubação houve diferença significativa. Os ovos que não sofreram o processo de repasse tiveram alta mortalidade nessa fase. Segundo Silva (2003) e Rocha et al. (2008) as principais causas de mortalidade final, principalmente entre o $18^{\circ}$ ao $21^{\circ}$ dia, estão relacionadas às condições do interior da máquina de incubação, como oscilações de temperatura de umidade na incubadora ou no nascedouro, manejo inadequado da transferência. Estas mortalidades embrionárias podem estar relacionadas a contaminação bacteriana dos ovos, devido a presença de trincas na casca. A casca oferece proteção para o embrião durante seu desenvolvimento e ameniza as flutuações de temperatura entre o meio interno e externo (Carvalho et al., 2007).

Ao avaliar ovos contaminados e desidratados não se obteve diferenças estatísticas significativas nos tratamentos testados (Tabela 3). Ressaltando que os ovos utilizados no estudo passaram por processo de fumigação na granja, o que pode ter diminuído alguns contaminantes presentes na casca. Os resultados são inferiores aos apresentados por Santos et al. (2007) que obtiveram 24,3\% de contaminação em ovos 
deformados e 10,9\% em ovos trincados. Os ovos desidratados podem ocorrer devido à excessiva perda de peso ou trincas na casca ocorridas antes ou durante o período de incubação (Barbosa et al., 2013).

Tabela 3. Percentual de ovos contaminados e desidratados de acordo com tipo de processo de classificação.

\begin{tabular}{lcc}
\hline & Contaminados & Desidratados \\
\hline Repassados & $0,38 \mathrm{a}$ & $1,38 \mathrm{a}$ \\
Não repassados & $0,50 \mathrm{a}$ & $0,32 \mathrm{a}$ \\
\hline $\mathrm{P}<$-value & 0,6830 & 0,2381 \\
\hline
\end{tabular}

Médias seguidas de letra iguais na coluna não diferem pelo teste Mann Whitney $(\mathrm{P}<0,05)$.

Na tabela 4 encontram-se uma simulação de custos de produção entre os tratamentos. Observa-se para os ovos classificados tem-se um custo de produção de pintinho menor em 13,2\%. Normalmente descartam-se ovos que apresentem pouca chance de eclosão, e que impliquem em pintinhos de baixa qualidade, como ovos muito grandes ou muito pequenos, trincado, sujos, deformados entre outros fatores (Cobb-Vantres, 2008).

A classificação dos ovos na granja ou incubatório obtém melhores índices de eclodibilidade, porém é necessário que haja pessoas treinadas ou equipamentos para separar e descartar os ovos que apresentam anormalidades. Outro aspecto a ser considerado é a necessidade do mercado de aves, portanto decisão de descartar depende da demanda do mercado, que aumenta ou diminui o valor do pinto de 1 dia.

Tabela 4. Simulação de custos de produção de ovos repassados e não repassados

\begin{tabular}{lcc}
\hline & Repassados & Não repassados \\
\hline Eclosão & $90,01 \%$ & $78,25 \%$ \\
$\mathrm{~N}^{\circ}$ de ovos & 1000 & 1000 \\
$\mathrm{~N}^{\circ}$ eclodidos & 901 & 782 \\
Valor/Ave & $\mathrm{R} \$ 1,25$ & $\mathrm{R} \$ 1,44$ \\
\hline
\end{tabular}

\section{Conclusão}

Nas condições em que o experimento foi realizado os ovos que passam por processo de classificação apresentam melhores índices de eclodibilidade e mortalidade embrionária.

\section{Referências bibliográficas}

Barbosa, V. M., Rocha, J. S. R., Baião, N. C., Mendes, P. M. M., Pompeu, M. A., Lara, L. J. C., . . . Cunha, C. E. (2013). Efeitos do momento de transferência dos ovos para o nascedouro e da idade da matriz pesada sobre o rendimento de incubação. Arquivo Brasileiro de Medicina Veterinária e Zootecnia, 65(6):1823-1830.

Carvalho, F. B., Stringhini, J. H., Jardim Filho, R. d. M., Leandro, N. S. M., Café, M. B. \& Deus, H. A. S. B. (2007). Qualidade interna e da casca para ovos de poedeiras comerciais de diferentes linhagens e idades. Ciência Animal Brasileira, 825-29.

Cobb-Vantres. (2008). Guia de manejo de incubação. Pelotas, Rio Grande do Sul, Brasil: Guapiaçu.

Cutts, J. A., Wilson, G. C. \& Fernández, S. (2007). Optimum egg quality: a practical approach. Sheffield, SY, England: 5M Publishing.

Francisco, N. S., Garcia, R. G., Nããs, I. A., Seno, L. O. \& Felix, G. A. (2013). Parâmetros que afetam o desenvolvimento embrionário de pintos de corte. Enciclopédia Biosfera, 91654-1661.

Mauldin, J. M. (2001). Factors affecting hatchability. In D. D. Bell \& W. D. Weaver (Eds.), Commercial egg production. Auburn, ALabama, USA: Auburn Academic Publishers. 
Narahari, D., Rajini, R. A., Srinivasan, G. \& Ramamurthy, N. (2000). Methods to improve the hatchability of checked chicken eggs. British Poultry Science, 41(2):178-181.

Narushin, V. G. \& Romanov, M. N. (2002). Egg physical characteristics and hatchability. World's Poultry Science Journal, 58(3):297-303.

Peebles, E. D. \& McDaniel, C. D. (2013). A practical manual for understanding the shell structure of broiler hatching eggs and measurements of their quality. Forestry and Veterinary Medicine at Mississippi State University, 171139.

Rocha, J. S. R., Lara, L. J. C., Baião, N. C., Cançado, S. V., Baião, L. E. C. \& Silva, T. R. (2008). Efeito da classificação dos ovos sobre o rendimento de incubação e os pesos do pinto e do saco vitelino. Arquivo Brasileiro de Medicina Veterinária e Zootecnia, 60(4):979-986.

Rovaris, E., Corrêa, G. d. S. S., Corrêa, A. B., Junior, J. G. C., Luna, U. V. \& Assis, S. D. (2014). Avaliação da incubação artificial de ovos deformados em matrizes pesadas. PUBVET, 8(18):21732291.

Santos, J. R. G., Fornari, C. M. \& Téo, M. A. (2007). Influência da qualidade da casca do ovo sobre índices de produtividade de um incubatório industrial. Ciência Rural, 37(2):524- 527.

Scarton, R. B. (2011). Estudo da avaliação do desempenho de ovos de um lote de avós de idade inicial, entre 24 e 34 semanas de idade. Trabalho de Monografia, Universidade Federal do Rio Grande do Sul, Porto Alegre, Rio Grande do Sul. Brasil.

Silva, E. N. (2003). Doenças de transmissão vertical. In M. Macari \& E. Gonzales (Eds.), Manejo da Incubação. Jaboticabal, São Paulo, Brasil: FACTA.

Recebido: 17 de janeiro, 2019.

Aprovado: 9 de fevereiro, 2019.

Publicado: 2 de março, 2019.

Licenciamento: Este artigo é publicado na modalidade Acesso Aberto sob a licença Creative Commons Atribuição 4.0 (CC-BY 4.0), a qual permite uso irrestrito, distribuição, reprodução em qualquer meio, desde que o autor e a fonte sejam devidamente creditados 